\title{
Renal artery pseudoaneurysm after robotic- assisted partial nephrectomy: case report
}

This article was published in the following Dove Press journal:

Robotic Surgery: Research and Reviews

21 July 2016

Number of times this article has been viewed

Emad S Rajih ${ }^{1,2}$

Mohammed F Alotaibi ${ }^{2}$

Waleed K Alkhudair ${ }^{2}$

'Department of Urology, Taibah University, Madinah, Saudi Arabia;

${ }^{2}$ Department of Urology, King Faisal

Specialist Hospital \& Research Center,

Riyadh, Saudi Arabia
Correspondence: Waleed K Alkhudair Department of Urology, King Faisal Specialist Hospital \& Research Center, PO Box 3354, MBC-83, Riyadh I I I I, Saudi Arabia

Tel +966 I I4422163

Fax+966 I | 442 430 I

Email walkhudair@gmail.com
Abstract: Renal artery pseudoaneurysm is an uncommonly recognized complication following partial nephrectomy. It is more common with trauma and percutaneous renal intervention. Furthermore, it is rarely reported with minimally invasive laparoscopic partial nephrectomy. Herein, we report the first case to our knowledge of renal artery pseudoaneurysm following a robotic-assisted partial nephrectomy.

Keywords: partial nephrectomy, renal pseudoaneurysm, robotic

\section{Introduction}

Partial nephrectomy (PN) is a standard of care for surgical treatment of small renal mass. Nowadays, with the introduction of minimal invasive laparoscopic and robotic renal surgery, PN has became increasingly popular in experienced hands. In spite of the advantages of minimal invasive approach with low morbidity and a better esthetic result, the limited working space and time make hemostasis more challenging. ${ }^{1}$

Vascular complications following PN have been reported previously. Furthermore, the most common form is immediate bleeding. However, delayed bleeding is a rare complication secondary to arteriovenous fistulae or renal artery pseudoaneurysm, with an incidence $\sim 1.7 \%$ in a large series of laparoscopic partial nephrectomy (LPN). ${ }^{2}$

Renal angiography and selective renal artery embolization are imperative in the management of delayed bleeding postoperatively. Furthermore, this is a safe and efficacious technique for managing these conditions. We report a first case to our knowledge of delayed bleeding after a robotic-assisted partial nephrectomy (RAPN).

\section{Case report}

A 55-year-old man was referred for RAPN of incidental renal mass. His preoperative computed tomography showed $3 \mathrm{~cm}$ mesophytic right renal mass that was abutting the renal vein at the renal sinus (Figure 1). He underwent elective RAPN in $45^{\circ}$ semilateral position. A total of five trocars were inserted, and a 3-arm da Vinci robotic surgical system was docked. Access to the right renal mass was achieved with complete mobilization of right kidney and hailer dissection. The mass was demarcated and then excised after clamping of renal artery and vein. Tumor bed was sewn with two different sutures. The first one was running 3-0 Maxon to close the collecting system and small vessels; then the edges of renal parenchyma were closed with interrupted 2-0 Maxon with hemo-lock applied over the stitches at the outer side. Total operative time 
A

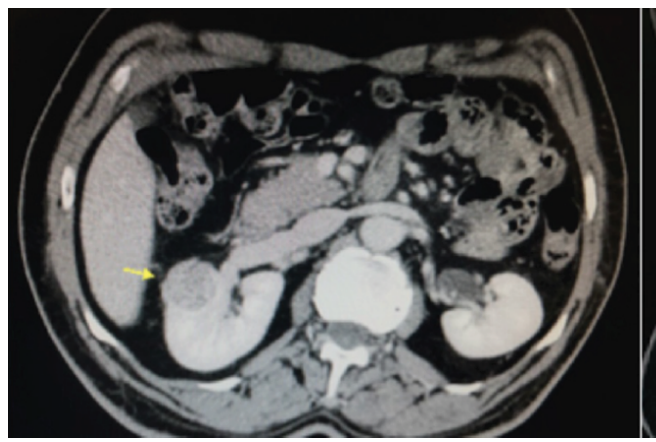

B

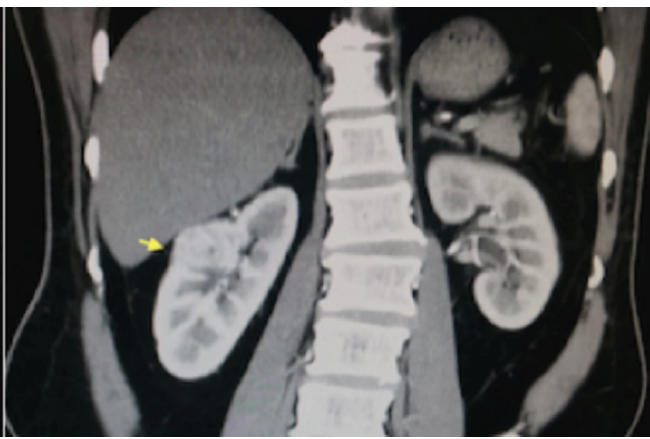

Figure I Computed tomography of the patients' right kidney.

Note: The yellow arrow points to the preoperative renal mass viewed both (A) trans-axially and (B) coronally.

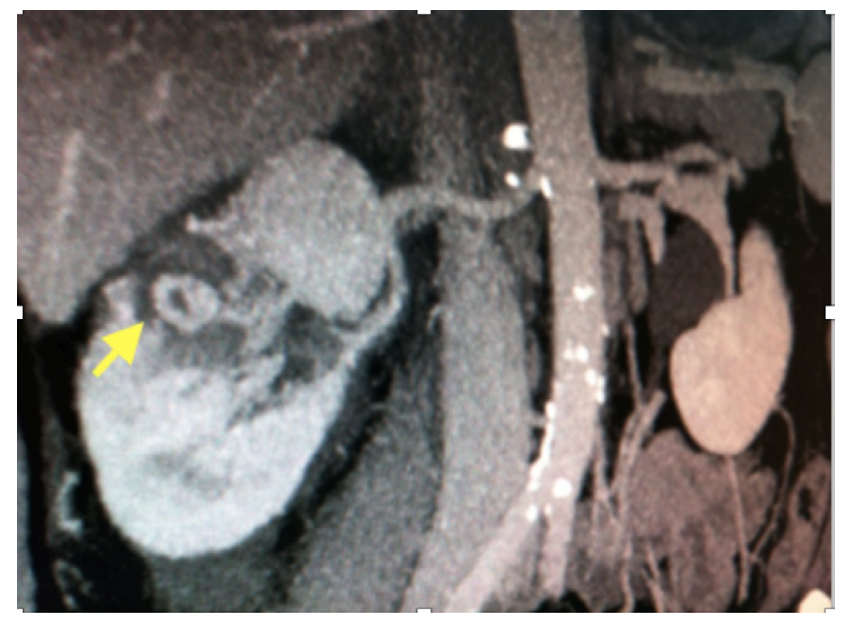

Figure 2 Computed tomography image of the patients' right kidney. Note: The yellow arrow pointing to the renal artery pseudoneurysm.

was 90 minutes, and warm ischemia time was 13 minutes. Floseal hemostatic matrix was applied over the suture line. The patient had an uneventful recovery and was discharged on the second postoperative day after Jackson Pratt drain removal. Histopathology confirmed moderately differentiated clear cell carcinoma with negative resection margins.

The patient was presented to the emergency department 22 days postoperatively with sudden gross hematuria and right-sided colicky flank pain (Figure 3). Physical examination showed normal level of consciousness and orientation. Vital signs revealed a temperature of $36.6^{\circ} \mathrm{C}$, heart rate of 88 beats/min, and blood pressure of $125 / 70 \mathrm{mmHg}$. No masses or tenderness were detected in abdominal examination. The patient had gross hematuria. Hemoglobin level was $11.7 \mathrm{~g} /$ $\mathrm{dL}$, and creatinine level was $95 \mu \mathrm{mol} / \mathrm{L}$. An emergency renal computed tomography showed segmental renal artery pseudoaneurysm arising from the tumor resection site (Figure 2). The patient had renal angiography that demonstrated a saccular pseudoaneurysm of the second segmental branch at the upper pole and embolization of the segmental renal artery with a coil (Tornado; Cook, Bloomington, IN, USA; and TRUFILL;
Cordis, Miami, FL, USA) (Figure 3). Serial blood tests were stable after embolization, and his urine became clear gradually over 24 hours before discharge. No signs of nephrotoxicity or postembolization syndrome were detected. The patient was discharged home on the second day after embolization.

Written informed consent was obtained from the patient however, ethical approval was not sought as per King Faisal Specialist Hospital requirements regarding case reports.

\section{Discussion}

Treatment of small renal mass has shifted from radical nephrectomy to nephron-sparing surgery in order to limit long-term morbidity of renal insufficiency. ${ }^{3}$ Incidental renal mass has increased nowadays with the new introduction and consideration of radiological indications. ${ }^{4}$ PNs are more complex than radical nephrectomy and more frequently result in complications. Customarily, PN has been performed via open approach surgery. However, duo to interest in the minimally invasive technique, Winfield et al performed the first LPN. ${ }^{5}$ Furthermore, with the introduction of the robotic system and its technical advantages, RAPN has been used for larger and more complicated lesions. ${ }^{6}$

The advantage of minimal invasive nephron sparing includes minimal analgesic requirement, hospital stay, and wound healing; however, it has equal oncological outcomes, local and distal recurrence, to open approach. ${ }^{1}$ The incidence of hemorrhage after $\mathrm{PN}$ is between $1 \%$ and $2 \%$. Hemorrhage secondary to renal artery pseudoaneurysm appears into the perirenal area or into the collecting system, whereby manifesting as hematuria. ${ }^{7,8}$ Renal artery pseudoaneurysm is relatively, a less common cause of gross hematuria and usually occurs after invasive procedures, such as percutaneous nephrostomy, renal artery angioplasty, renal biopsy, blunt or penetrating trauma, and renal surgery. ${ }^{9,10}$ An artery that is partially transected during tumor resection could consequently 
A

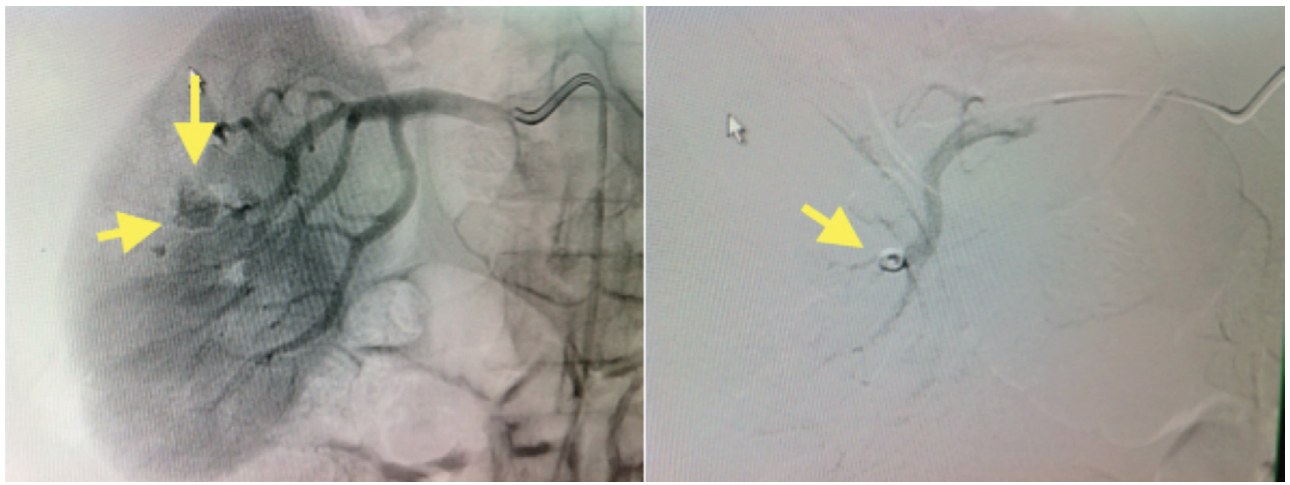

Figure 3 Right renal artery angiogram.

Notes: The yellow arrows pointing to $(\mathbf{A})$ active bleeding before embolization and $(\mathbf{B})$ right renal artery angiography after superselective embolization.

bleed into a contained space, particularly near the apex of wedge resection. The other mechanism could be a puncture hole made into a vessel during tumor bed closure where the initial needle placement is removed. ${ }^{2}$ Sudden gross hematuria and flank pain postoperatively are strongly characteristic of renal artery pseudoaneurysm as reported in our patient. It is also imperative to consider pseudoaneurysm as a potential delayed complication in a hypovolemic patient following PN.

Meta-analysis review of the renal artery pseudoaneurysm by Jain et al showed higher incidence in LPN than open approach. However, this study needs to be conducted with a higher quality of evidence to investigate the advantages of this operative approach. Angioembolization of the renal artery pseudoaneurysm was the first line of intervention in almost all patients of his series, and it was successful in $96 \%$ of those who were embolized. Nephrectomy was required after failure of angioembolization. ${ }^{11}$

Hyams et $\mathrm{l}^{12}$ reported their multicenter experience with iatrogenic vascular lesions and clinical outcomes after PN. The incidence of vascular lesions was 20 of 998 (2\%) patients (17 patients had pseudoaneurysm and three patients had arteriovenous fistula). In fact, several case series and reports had published these occurrences only after LPN. In Hyams' series, their group did not verify the incidence after robotic versus LPN. However, they could not evaluate possible risk factors for vascular lesions due to low incidence. In LPN, we hypothesized that handling and controlling of vascular and collecting system defects during PN are less precise with less dexterity and magnification than robotic approach. Nonetheless, the incidence of vascular lesion after these two modalities has not yet been tested yet. Singh and Gill ${ }^{13}$ conducted a retrospective review of 345 LPN during a 5-year period. Incidence of aneurysmal hemorrhage after surgery was detected in six patients (1.7\%). Median tumor size was $3.5 \mathrm{~cm}$, warm ischemia time was 32 minutes, and blood loss was $175 \mathrm{cc}$. Interestingly, all patients had pelvicaliceal system entry and were repaired by suture. Delayed bleeding occurred at a range of 8-15 days (median 12 days). All patients had renal artery pseudoaneurysm that was detected by renal angiography at a third or fourth segmental artery. All patients were treated successfully by percutaneous embolization.

Pseudoaneurysm in urological practice can occur and happens mostly after renal and pelvic surgery. ${ }^{14,15}$ With increasing use of the robotic system in the surgical field, many reports have been published on the occurrence of pseudoaneurysm other than in robotic renal surgery. Atmaca et al reported the occurrence of delayed massive hemorrhage due to external iliac artery pseudoaneurysm following robotic-assisted radical cystectomy and lymph node dissection. Surprisingly, aneurysm was concomitant with ureter-iliac fistula, which was managed by endovascular stent that was inserted at the level of aneurysm and the fistula. ${ }^{16}$ Furthermore, Feng et al described a case of delayed presentation of recurrent hematuria secondary to an accessory pudendal artery pseudoaneurysm after robotic assisted-radical prostatectomy. Angiography and stenting were fundamental for diagnosis and successful treatment of this rare entity. ${ }^{17}$

Although LPN was associated with higher incidence of pseudoaneurysm in comparison to open technique, there is still no report to elaborate the risk of pseudoaneurysm in the robotic system in comparison to laparoscopic or open approach. However, the characteristic advantage of the da Vinci surgical robotic system over the laparoscopic technique, including the better visualization with three dimensions and the advantage of endowrist movement during intracorporeal suturing of renal tumor bed, might decrease the incidence in the future compared to laparoscopic technique.

\section{Conclusion}

Renal artery pseudoaneurysm is a newly reported complication after RAPN. The patients with renal artery 
pseudoaneurysm can be identified and treated successfully with percutaneous angiography and embolization. Low incidence of pseudoaneurysm post-RAPN might be considered in the future due to robotic advantageous technical effect during surgery.

\section{Disclosure}

The authors report no conflicts of interest in this work.

\section{References}

1. Gill IS, Kavoussi LR, Lane BR, et al. Comparison of 1,800 laparoscopic and open partial nephrectomies for single renal tumors. J Urol. 2007;178(1):41-46.

2. Singh D, Gill IS. Renal artery pseudoaneurysm following laparoscopic partial nephrectomy. J Urol. 2005;174(6):2256-2259.

3. Touijer K, Jacqmin D, Kavoussi L, et al. The expanding role of partial nephrectomy: a critical analysis of indications, results and complications. Eur Urol. 2010;57(2):214-222.

4. Hollenbeck BK, Taub DA, Miller DC, Dunn RL, Wei JT. National utilization trends of partial nephrectomy for renal cell carcinoma: a case of under utilization? Urology. 2006;67(2):254-259.

5. Winfield HN, Donovan JF, Godet AS, Clayman RV. Laparoscopic partial nephrectomy: initial case report for benign disease. J Endourol. 1993;7(6):521-526.

6. Heuer R, Gill IS, Guazzoni G, et al. A critical analysis of the actual role of minimally invasive surgery and active surveillance for kidney cancer. Eur Urol. 2012;57(2):223-232.

7. Ghavamian R, Cheville J, Lohse CM, Weaver AL, Zincke H, Blute ML. Renal cell carcinoma in the solitary kidney: an analysis of complications and outcome after nephron sparing surgery. Clin Urol. 2002;168(2):454-459.
8. Corman JM, Penson DF, Hur K. Comparison of complications after radical and partial nephrectomy: results from the National Veterans Administration Surgical Quality Improvement Program. $\mathrm{Br} J$ Urol. 2000;86(7):782-789.

9. Kang KP, Kwak HS, Han YM, et al. A delayed case of renal artery pseudoaneurysm presented with gross hematuria and azotemia in solitary kidney following percutaneous nephrostomy: treated by transcatheter coil embolization. Int Urol Nephrol. 2008;40(3):811-813.

10. Matos A, Moreira A, Mendonça M. Renal arteriovenous fistula after nephrectomy. Ann Vasc Surg. 1992;6(4):378-380.

11. Jain S, Nyirenda T, Yates J, Munver R. Incidence of renal artery pseudoaneurysm following open and minimally invasive partial nephrectomy: a systematic review and comparative analysis. J Urol. 2013;189(5):1643-1648.

12. Hyams ES, Pierorazio P, Proteek O, et al. Iatrogenic vascular lesions after minimally invasive partial nephrectomy: a multiinstitutional study of clinical and renal functional outcome. Urology. 2011;78(4):820-826.

13. Singh D, Gill IS. Renal artery pseudoaneurysm following laparoscopic partial nephrectomy. J Urol. 2005;174(6):2256-2259.

14. Lopes RI, Mitre AI, Rocha FT, Piovesan AC, Da Costa OF, Karakhanian W. Case report: late recurrent hematuria following laparoscopic radical prostatectomy may predict internal pudendal artery pseudoaneurysm and arteriovenous fistula. J Endourol. 2009;23(2):297-300.

15. Sutherland DE, Williams SB, Rice D, Jarrett TW, Engel JD. Vascular pseudoaneurysms in urology: clinical characteristics and management. J Endourol. 2010;24(6):915-921.

16. Atmaca AF, Canda AE, Gumus M, Asil E, Balbay MD. Delayed massive hemorrhage due to external iliac artery pseudoaneurysm and ureteroiliac artery fistula following robotic radical cystectomy and intracorporeal Studer pouch reconstruction: endovascular management of an unusual complication. Can Urol Assoc J. 2013;7(9-10):E605-E608.

17. Feng T, Patel HD, Allaf ME. Pudendal artery pseudoaneurysm after robot-assisted laparoscopic radical prostatectomy. Urology. 2013;81(1):e5-e6.
Robotic Surgery: Research and Reviews

\section{Publish your work in this journal}

Robotic Surgery: Research and Reviews is an international, peer reviewed, open access, online journal publishing original research, commentaries, reports, and reviews on the theory, use and application of robotics in surgical interventions. Articles on the use of supervisory-controlled robotic systems, telesurgical devices, and shared-control systems are

\section{Dovepress}

invited. The manuscript management system is completely online and includes a very quick and fair peer review system, which is all easy to use. Visit http://www.dovepress.com/testimonials.php to read real quotes from published authors. 